\title{
Finite element analysis of basal heave stability for braced excavations in clays
}

\author{
Zhang Fan ${ }^{\text {i) }}$ and Anthony T. C. Goh ${ }^{\text {ii) }}$ \\ i) PhD Graduate Student, School of Civil and Environmental Engineering, Nanyang Technological University, Singapore. \\ ii) Associate Professor, School of Civil and Environmental Engineering, Nanyang Technological University, Singapore
}

\begin{abstract}
The basal heave stability of braced excavations in clay soils is one of the key considerations in both design and during construction. The finite element method with shear strength reduction (SSR) is increasingly being used for estimating the safety factor for geotechnical engineering problems. In this paper, results of basal heave stability for deep narrow braced excavations in terms of factor of safety (FS) and stability number $\left(N_{s}\right)$ using two-dimensional finite element method with SSR are presented. Total stress finite element simulations are carried out to parametrically analyse the effects of system stiffness, undrained shear strength and excavation geometry on the base stability of braced excavations in different clay soils. For the cases considered, the study shows that the system stiffness has minimal influence on the factor of safety against basal heave. The stability number $N_{s}$ calculated from finite element analysis is independent of the undrained shear strength of clays. Also, the $N_{s}$ value decreases almost linearly as the ratio of the depth to the width of the excavation increases. The failure zone from finite element analysis is more extensive than that proposed by Terzaghi. Comparison of the factor of safety between the calculations from conventional methods and from finite element analysis indicate that the modified Terzaghi's method that considers the wall embedment depth are in close agreement with the results based on the plane strain finite element analyses.
\end{abstract}

Keywords: basal heave stability, finite element analysis, braced excavations, clays

\section{INTRODUCTION}

The basal heave stability assessment for deep braced excavations in clay soils is important and necessary to carry out in practice. Conventional methods such as Terzaghi's method (Terzaghi 1943) are commonly used, but many of these classical methods were developed decades ago, when the computation technology was not as developed as today. The finite element method (FEM) with shear strength reduction (SSR) has been recognised as a robust approach (Matsui and San 1992, Griffiths and Lane 1999, Do et. al. 2013, etc.) for estimating the safety factor for geotechnical engineering problems. But there has been limited literature reported on the assessment of the factor of safety for deep braced excavations in clay soils using this approach. Besides, it is useful to compare the factor of safety between numerical calculations and conventional methods, so that guidelines can be highlighted for engineering design and practice.

In this paper, the investigation of basal heave stability for deep narrow braced excavations using finite element analysis is carried out through assessing the factor of safety (FS) and the stability number $\left(N_{s}\right)$. A total of 72 plane strain FE calculations are conducted to analyse various factors affecting the base stability of braced excavations in different clay soils. The factors considered include the system stiffness, the undrained shear strength of the clay soils and the geometry of the excavation and wall. A comparison of the factor of safety FS between FEM and several conventional methods is also carried out.

\section{CONVENTIONAL METHODS FOR BASAL HEAVE STABILITY - AN OVERVIEW}

Terzaghi (1943) first proposed a failure mechanism for basal heave stability for wide excavations, which was developed for wide excavations with sheetpile walls. One of the modifications suggested by Terzaghi (1943) also takes the wall embedment depth $D$ into account. Bjerrum and Eide (1956) provided an approach for determining the factor of safety for narrow excavations to complement Terzaghi's method. A bearing capacity factor $N_{\mathrm{c}}$ is introduced, which can be determined as a function of the $H / B$ ratio and $L / B$ ratio, where $H$ refers to the excavation depth, $L$ refers to the excavation length and $B$ refers to the excavation width. Goh (1994) studied the basal heave stability for wide braced excavations in soft clay by conducting a series of finite element analysis using the nodal displacement method proposed by Goh (1990). Multiplier factors are 
proposed which take the clay thickness, the wall penetration depth and the wall stiffness into consideration. These methods are summarised in Table 1.

Table 1. Summary of conventional methods for the basal heave calculation

\begin{tabular}{lll}
\hline Factor of Safety & Notes & Reference \\
\hline $\mathrm{FS}_{\mathrm{T} 1}=\frac{5.7 c_{u} B_{1}}{\gamma H B_{1}-c_{u} H}$ & $\begin{array}{l}\text { Wide excavations } \\
(B>H) \text { of } \\
\text { rectangular shape }\end{array}$ & $\begin{array}{l}\text { Terzaghi } \\
(1943)\end{array}$ \\
\hline $\mathrm{FS}_{\mathrm{T} 2}=\frac{5.14 c_{u}+\sqrt{2}\left(\frac{H_{\mathrm{w}}}{B}\right)+2 c_{u}\left(\frac{D}{B}\right)}{\text { Embedded wall }}$ \\
$\begin{array}{l}\gamma H \\
\text { considered; } \\
\text { Perfectly smooth } \\
\text { footing }\left(N_{c}=5.14\right)\end{array}$ & $\begin{array}{l}\text { Terzaghi } \\
(1943)\end{array}$ \\
\hline $\mathrm{FS}_{\mathrm{B \& E}}=\frac{c_{u} N_{c}}{\gamma H+q}$ & $\begin{array}{l}\text { Narrow excavations } \\
(B<H)\end{array}$ & $\begin{array}{l}\text { Bjerrum\& } \\
\text { Eide } \\
(1956)\end{array}$ \\
\hline $\mathrm{FS}_{\mathrm{Gh}}=\frac{c_{u} N_{h}}{\gamma H+q} \mu_{t} \mu_{d} \mu_{\mathrm{w}}$ & $\begin{array}{l}\text { Homogenous and } \\
\text { constant } c_{u} ; H / B< \\
0.6\end{array}$ & $\begin{array}{l}\text { Goh } \\
(1994)\end{array}$ \\
\hline
\end{tabular}

\section{DEVELOPMENT OF THE FINITE ELEMENT MODEL FOR BASAL HEAVE STABILITY}

Plane strain finite element analyses using Plaxis 2011 (Brinkgreve et al., 2011) were carried out in which various geometrical factors, wall stiffness and undrained shear strength properties were varied. Total stress Mohr-Coulomb constitutive soil model was employed in the finite element analysis.

\subsection{Geometry}

The cross-section of the excavation is depicted in Fig. 1. The geometrical parameters that were varied included the excavation depth $H(9 \mathrm{~m}, 12 \mathrm{~m}, 15 \mathrm{~m}$ and $16 \mathrm{~m}$ ), the wall penetration depth $D$, the clay thickness below the current excavation level $T$, the net clay thickness at the final excavation level $T_{n}(32 \mathrm{~m}, 14 \mathrm{~m}$, $10 \mathrm{~m}$ ), and the embedment depth at the final excavation level $D_{n}(4 \mathrm{~m}, 0)$. For a wall of height $H_{w}(20 \mathrm{~m})$, as the excavation depth $H$ is increased, there is a corresponding decrease in the depth of embedment $D$ $\left(=H_{w}-H\right)$. The notations $T_{n}$ and $D_{n}$ correspond to the special case when $H$ was at the final excavation level. The excavation width $B$ was $20 \mathrm{~m}$ for all the cases considered.

\subsection{Properties of clay soils, retaining walls and retaining structures}

Clays with three different undrained shear strengths $\left(c_{u}\right)$ were assumed as shown in Table 2. The soil stress-strain behaviour was modelled using the Mohr-Coulomb soil model with a Poisson's ratio $v=$ 0.495 and $E_{u} / c_{u}=300$. Total stress analyses were carried out to determine the factor of safety using the SSR method. Fig. 2 shows a typical plot of the plastic points for the case with $H=16 \mathrm{~m}$ and $c_{u}=40 \mathrm{kPa}$.
Table 2. Mohr-Coulomb soil properties in basal heave stability analysis.

\begin{tabular}{llll}
\hline Soil & $\gamma\left(\mathrm{kN} / \mathrm{m}^{3}\right)$ & $C u(\mathrm{kPa})$ & $E_{u}\left(\mathrm{kN} / \mathrm{m}^{2}\right)$ \\
\hline $\mathrm{A}$ & 16 & 40 & $1.2 \mathrm{E} 04$ \\
\hline B & 16 & 60 & $1.6 \mathrm{E} 04$ \\
\hline $\mathrm{C}$ & 16 & 70 & $2.1 \mathrm{E} 04$ \\
\hline
\end{tabular}

Table 3. Retaining wall properties.

\begin{tabular}{llll}
\hline Wall Type & $\begin{array}{l}\text { System } \\
\text { stiffness } S\end{array}$ & $E I\left(\mathrm{kNm}^{2} / \mathrm{m}\right)$ & $E A(\mathrm{kN} / \mathrm{m})$ \\
\hline Flexible & 32 & $5.04 \mathrm{E}+04$ & $3.427 \mathrm{E}+06$ \\
\hline Medium & 320 & $5.04 \mathrm{E}+05$ & $3.427 \mathrm{E}+07$ \\
\hline Stiff & 3200 & $5.04 \mathrm{E}+06$ & $3.427 \mathrm{E}+08$ \\
\hline
\end{tabular}

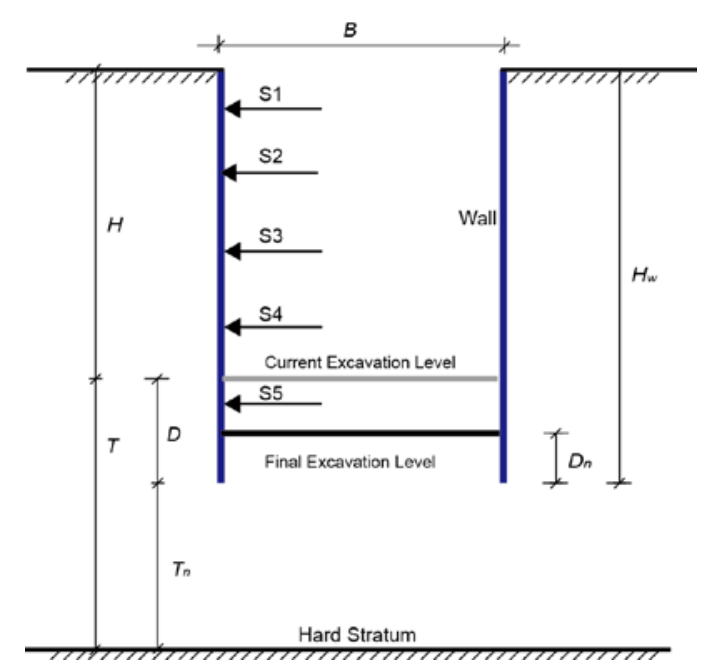

Fig. 1. Geometry of braced excavation.

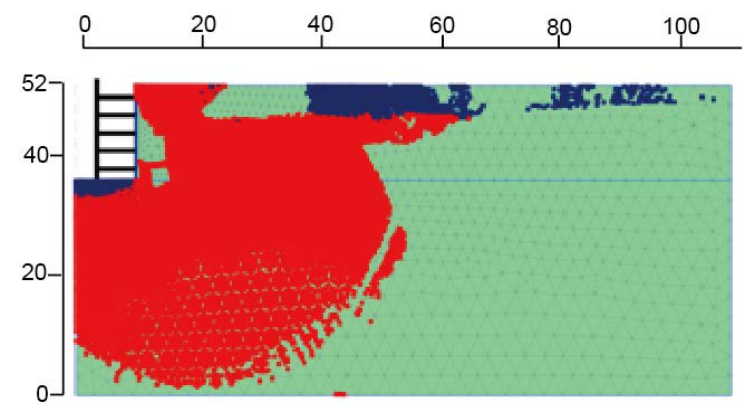

Fig. 2. A typical plastic points (red dots) plot from FEM

To assess the influence of the wall stiffness on the basal heave stability, walls with three different system stiffnesses are employed and denoted as flexible, medium and stiff walls as shown in Table 3. The system stiffness $S$ (Clough and O’Rourke, 1990) was defined as $E I /\left(\gamma_{w} H_{\text {avg }}{ }^{4}\right)$, where $E I$ is the wall stiffness and $H_{\text {avg }}$ is the average vertical spacing of the struts.

To increase the accuracy of the results, very fine meshes are generated with a global error of 0.01 in the SSR evaluation, according to the Plaxis Manual (Brinkgreve et al., 2011). 


\section{EFFECTS OF VARIOUS FACTORS ON BASAL HEAVE STABILITY}

\subsection{Effect of system stiffness}

Fig. 3 shows the results of the factor of safety versus system stiffness for various $H / B$ ratios $(0.45,0.60,0.75$, 0.80 ) for the cases with $c_{u}=40 \mathrm{kPa}, D_{n}=4 \mathrm{~m}, T_{n}=32$ $\mathrm{m}$. Similar trends were observed for $c_{u}=60 \mathrm{kPa}$ and 70 $\mathrm{kPa}$. The results indicate that system stiffness has minimal influence on the base stability of the excavation for the cases considered.

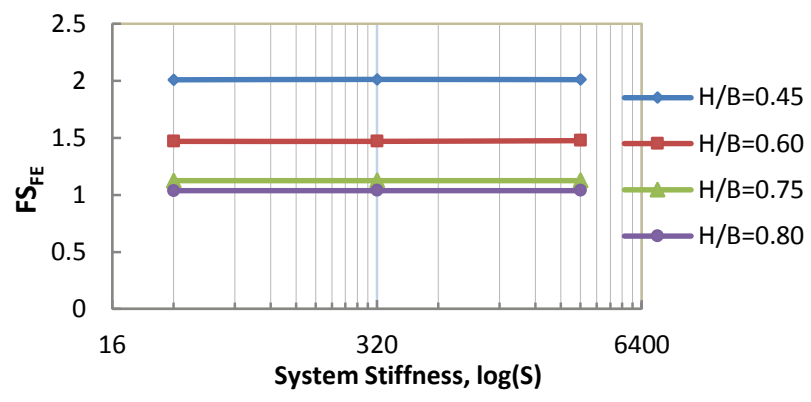

Fig. 3. Logarithm of system stiffness versus $\mathrm{FS}_{\mathrm{FE}}\left(c_{u}=40 \mathrm{kPa}\right.$, $D_{n}=4 \mathrm{~m}, T_{n}=32 \mathrm{~m}$ )

\subsection{Effect of undrained shear strength}

In order to assess the effects of the various parameters on the factor of safety for different undrained shear strength, a nondimensional stability number $N_{s}$ is introduced. $N_{s}$ is defined as:

$$
N_{s}=\frac{\mathrm{FS} \gamma H}{c_{u}}
$$

Since the wall stiffness does not influence the FS from plane strain analysis, only $N_{\mathrm{s}}$ values from the cases with flexible walls are shown in Figure 4. From the figure, it can be seen that the stability number is almost independent of the undrained shear strength.

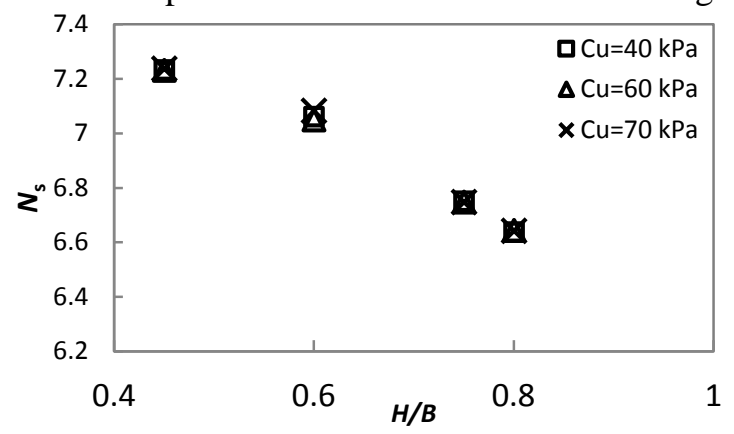

Fig. 4. $N_{s}$ values versus $H / B$ ratio for different undrained shear strengths (flexible wall, $D_{n}=4 \mathrm{~m}, T_{n}=32 \mathrm{~m}$ ).

\subsection{Effect of geometry}

From Fig.4, it can also be seen that the $H / B$ ratio is approximately linearly related to $N_{s}$, and significantly influences the basal heave stability. However, it is worth noting that the range of the $H / B$ ratio considered is only from 0.45 to 0.8 .

Fig 5 indicates that the $T / B$ ratio is also another important parameter affecting the basal heave stability. The $N_{s}$ value decreases sharply particularly when the $T / B$ ratio is less than 1.0. As shown in Table 4, the net embedment depth $D_{n}$ is another important parameter as increasing $D_{n}$ leads to the increase in $N_{s}$.

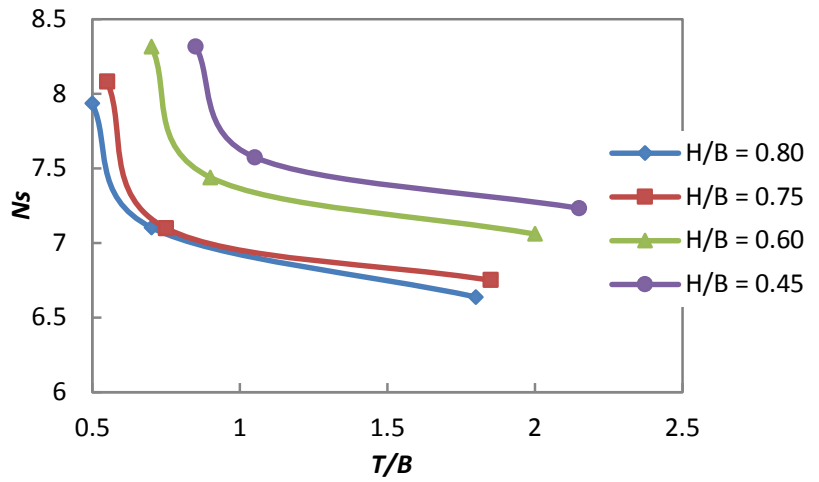

Fig. 5. $N_{s}$ values versus $T / B$ ratio (flexible wall, $D_{n}=4 \mathrm{~m}, C_{u}=$ $40 \mathrm{kPa})$.

Table 4. $N_{s}$ values for different $D_{n}$ (flexible wall, $T_{n}=36 \mathrm{~m}, c_{u}=$ $40 \mathrm{kPa})$

\begin{tabular}{lll}
\hline$H / B$ & \multicolumn{2}{l}{$N_{s}$} \\
\hline & $D_{n}=0$ & $D_{n}=4 \mathrm{~m}$ \\
\hline 0.45 & 6.65 & 7.23 \\
\hline 0.60 & 6.39 & 7.06 \\
\hline 0.75 & 6.14 & 6.75 \\
\hline 0.80 & - & 6.64 \\
\hline
\end{tabular}

\section{COMPARISONS OF FACTOR OF SAFETY: FEM AND CONVENTIONAL METHODS}

Comparisons are made between the factor of safety results from the finite element analysis and conventional methods.

As highlighted previously, the finite element analysis indicates that the wall stiffness has minimal effect on the factor of safety for the cases considered. Therefore, the FE results for the flexible wall cases are plotted in Fig 6. Also shown in Fig. 6 are the FS values determined using Terzaghi's method $\left(\mathrm{FS}_{\mathrm{T} 1}\right)$, Goh's method $\left(\mathrm{FS}_{\mathrm{Gh}}\right)$, modified Terzaghi's method $\left(\mathrm{FS}_{\mathrm{T} 2}\right)$, and Bjerrum and Eide's method $\left(\mathrm{FS}_{\mathrm{BE}}\right)$. One of the limitations of Goh's method is that it can only be used when $H / B$ ratio is smaller than 0.6.

Generally, Terzaghi's method overestimates the factor of safety for the cases with $c_{u}=60 \mathrm{kPa}$ and 70 $\mathrm{kPa}$. The plastic points (red dots) plot in Fig 2 also suggests that the failure zone is beyond the side and bottom of that assumed in Terzaghi's method. The Bjerrum and Eide's method gives smaller FS values when $H / B$ ratio is small. The results based on the modified Terzaghi's method are in close agreement with the results based on the plane strain finite element 
analyses.
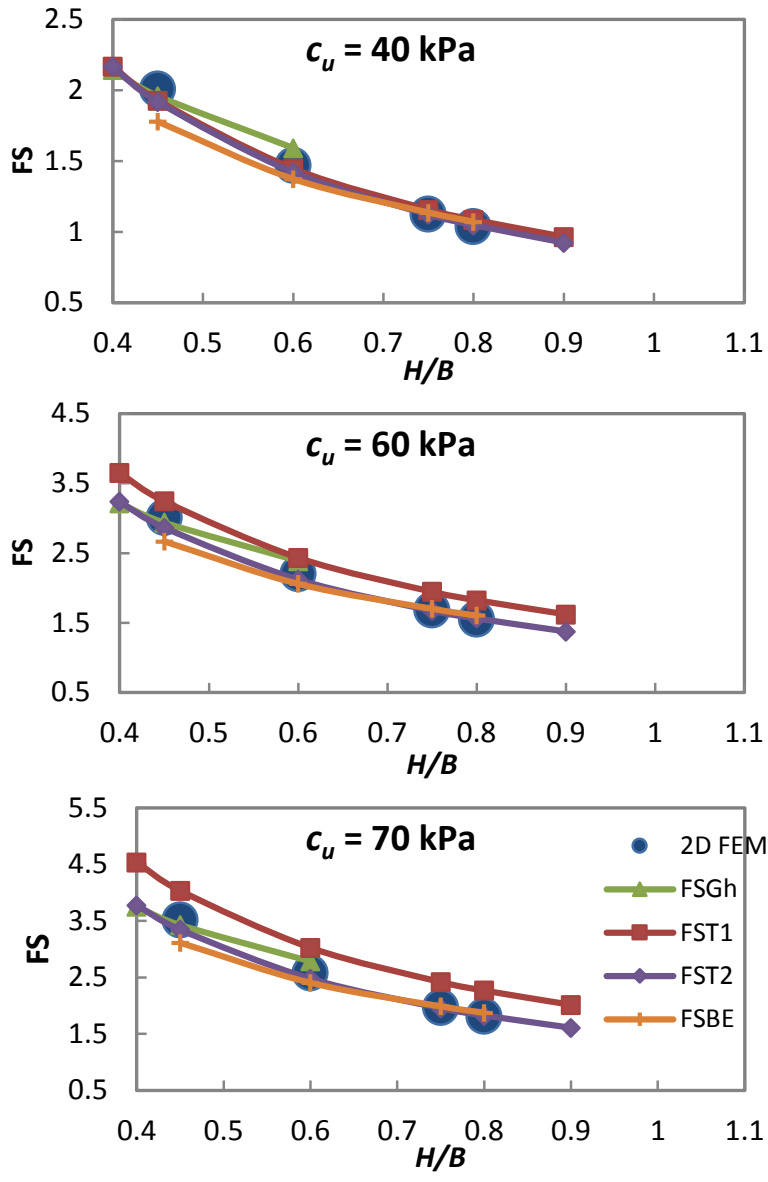

Fig. 6. Comparison of FS: FEM and conventional methods for $c_{u}=40 \mathrm{kPa}, 60 \mathrm{kPa}$ and $70 \mathrm{kPa}\left(D_{n}=4 \mathrm{~m}, T_{n}=32 \mathrm{~m}\right)$

\section{CONCLUSIONS}

In this paper, two-dimensional FE simulations for estimating the basal heave stability of braced excavations under total stress conditions are conducted. The Mohr-Coulomb constitutive soil model is employed. The parameters studied include the retaining system stiffness, the undrained shear strength of the clay soils and geometrical properties of the wall and excavation.

To conclude, the system stiffness has minimal influence on the factor of safety against basal heave calculated from two-dimensional finite element analysis for the cases considered. The stability number Ns values calculated from two-dimensional analysis are independent of undrained shear strength. The increase of $H / B$ ratio leads to a linear decrease in $N s$ values. Decreasing $T / B$ ratio and increasing $D_{n}$ helps to increase the basal heave stability. Comparisons between the FS from some conventional methods are made and summarised in Table 5.

Recent FEM studies by Do et. al. (2013) have shown that the intersection method are generally in good with field observations. The main limitation of this approach is the necessity to perform repeated analyses to obtain the FS. This will be considered in subsequent studies.

Table 5. Summary of comparisons between conventional methods and FEM

\begin{tabular}{ll}
\hline Conventional methods & Comments \\
\hline Terzaghi $\left(\mathrm{FS}_{\mathrm{T} 1}\right)$ & generally overestimates $\mathrm{FS}$ FE \\
\hline Modified Terzaghi $\left(\mathrm{FS}_{\mathrm{T} 2}\right)$ & close agreement with $\mathrm{FS}$ FE \\
\hline Goh ( $\left.\mathrm{FS}_{\mathrm{Gh}}\right)$ & close agreement with $\mathrm{FS}$ FE but only \\
& applicable when $H / B$ is smaller than \\
& 0.6 \\
\hline Bjerrum and Eide's (FS & underestimates when $H / B$ is small \\
\hline
\end{tabular}

\section{REFERENCES}

1) Bjerrum, L., and Eide, O. (1956). Stability of Strutted Excavations in Clay. Géotechnique, 6(1), 32-47.

2) Brinkgreve, L. B. J., Engin, E. and Swolfs, W. M. (2011). Plaxis Manual, PLAXIS bv, Netherlands.

3) Clough, G. W., and O' Roure, T. D. Construction Induced Movements of in Situ Walls. Proc., Design and Performance of Earth Retaining Structures, 439-470.

4) Do, T., Ou, C., and Lim, A. (2013). Evaluation of Factors of Safety against Basal Heave for Deep Excavations in Soft Clay Using the Finite-Element Method. Journal of Geotechnical and Geoenvironmental Engineering, 139(12), 2125-2135.

5) Goh, A. T. C. (1990). Assessment of Basal Stability for Braced Excavation Systems Using the Finite Element Method. Computers and Geotechnics, 10 (4), 325-338.

6) Goh, A. T. C. (1994). Estimating Basal - Heave Stability for Braced Excavations in Soft Clay. Journal of Geotechnical Engineering, 120 (8), 1430-1436.

7) Griffiths, D. V., and Lane, P. A. (1999). Slope Stability Analysis by Finite Elements. Géotechnique, 49(3), 387-403.

8) Matsui, T., and San, K. C. (1992). Finite Element Slope Stability Analysis by Shear Strength Reduction Technique. Soils and Foundations, 32(1), 59-70.

9) Terzaghi, K. (1943). Theoretical Soil Mechanics, Wiley, New York. 